\title{
Antibiotic resistance and detection of the sul2 gene in urinary isolates of Escherichia coli in patients from Brazil
}

\author{
Aline Teichmann ${ }^{1}$, Homero Neto de Cunha Agra ${ }^{2}$, Luciana de Souza Nunes ${ }^{1}$, Marion Pereira da Rocha ${ }^{3}$, \\ Jane Dagmar Pollo Renner ${ }^{2}$, Lia Gonçalves Possuelo², Marcelo Carneiro², Alexandre Rieger ${ }^{2}$, Lisianne \\ Brittes Benitez ${ }^{2}$, Andréia Rosane de Moura Valim²
}

${ }^{1}$ Universidade Federal do Rio Grande do Sul, Porto Alegre, Brazil

${ }^{2}$ Universidade de Santa Cruz do Sul, Santa Cruz do Sul, Brazil

${ }^{3}$ Laboratory Enzilab, Santa Cruz do Sul, Brazil

\begin{abstract}
Introduction: The present study aimed to assess the antibiotic resistance profiles and detect the presence of the sul2 gene in sulfamethoxazole-susceptible and resistant isolates of Escherichia coli obtained from outpatients and inpatients with urinary tract infections. Methodology: The resistance profiles of 739 strains were assessed and the presence of the sul2 gene in 100 isolates was tested.

Results: The antibiotics with the highest resistance rates were ampicillin (57.4\%) and trimethoprim-sulfamethoxazole (44.7\%). The presence of the gene sul 2 was detected in $66.7 \%$ of outpatient samples and $67.9 \%$ of inpatient samples.

Conclusions: Our results demonstrate that $E$. coli isolates exhibit high resistance to various classes of antibiotics, highlighting the need for developing strategies to help in prescribing antibiotics.
\end{abstract}

Key words: urinary tract infection; antibiotic agents; resistance

J Infect Dev Ctries 2014; 8(1):039-043. doi:10.3855/jidc.3380

(Received 05 February 2013 - Accepted 26 March 2013)

Copyright (C) 2014 Teichmann et al. This is an open-access article distributed under the Creative Commons Attribution License, which permits unrestricted use, distribution, and reproduction in any medium, provided the original work is properly cited.

\section{Introduction}

The urinary tract infection (UTI) is one of the most common infections, with significant morbidity and high medical costs [1]. Due to its high prevalence, it is regarded as a serious public health problem. Therefore, knowledge about the prevalence of uropathogens, their sensitivity to antibiotics, and awareness of the severity of this condition are important factors in empirical therapy, which is part of the current approach to managing UTIs [2]. The most frequently isolated etiologic agent of UTIs is Escherichia coli, which accounts for $80 \%$ or more of the total infections acquired in the community and $40 \%$ of the infections acquired in hospital settings [3].

UTIs are among the four main hospital infections because of the frequent need of instrumentation of the urinary tract, both for diagnostic purposes and for urine drainage. Catheter-associated urinary tract infections remain the most common nosocomial infections; approximately $80 \%$ of the cases of hospital UTIs are related to the use of a urinary catheter $[4,5]$.

Over the last few years, there has been a progressive increase in resistance of $E$. coli to the antibiotic agents commonly used in the treatment of UTIs. In uncomplicated UTIs, empirical antibiotic treatment is recommended when the main pathogen and the local or regional resistance profile are known. This treatment raises much debate because $20 \%$ to $50 \%$ of E. coli are resistant to some first-line antibiotics such as trimethoprim-sulfamethoxazole (SMT) [6,7].

Sulfamethoxazole is a sulfonamide antibiotic commonly used in association with trimethoprim as a first-line option to treat urinary tract infections. Among the resistance mechanisms for sulfonamide antibiotics in E. coli are described sul1, sul2, and sul3 genes. The sul2 gene can cause high-level expression of dihydropteroate synthase, mediating resistance. Many studies around the world have demonstrated a high association between the presence of the sul2 gene and resistance to sulfamethoxazole [8].

The sul2 gene can be transferred between enteric pathogens via plasmids or transposable DNA elements. Horizontal gene transfer and clonal expansion in bacteria have contributed to the spread of antibiotic resistance. This fact may be one of the 
explanations for the increased levels of resistance to antibiotics. A number of studies have demonstrated that resistance to sulfamethoxazole is increasingly related to the presence of the sul2 gene [9].

This study aimed to assess the levels of resistance of urinary E. coli to antibiotics and to detect the presence of the sul2 gene in isolates resistant to sulfamethoxazole in inpatients and outpatients from Santa Cruz do Sul, Brazil.

\section{Methodology}

Ethical considerations

This study was approved by the Universidade de Santa Cruz do Sul Research Ethics Committee under protocol number 1217/05.

\section{Type of study and sampling}

This study was a cross-sectional, observational survey using quantitative delineation. A total of 739 urinary isolates, $87.3 \%$ from outpatients, of E. coli were analyzed for susceptibility to the antibiotic agents most commonly used in the treatment of UTIs; of these, 100 isolates were randomly selected for detection of the sul 2 gene, the majority (72\%) from outpatients. The isolates were obtained between July 2004 and August 2007 from the Enzilab laboratory. This laboratory performs clinical analysis for a hospital in the city of Santa Cruz do Sul.

\section{Microorganism identification}

Urine samples were cultivated on MacConkey agar (Oxoid, Basingstoke, UK) and Cysteine Lactose Electrolyte Deficient (CLED) (Oxoid, Basingstoke, UK). Those that grew to a density greater than or equal to $10^{5} \mathrm{CFU} / \mathrm{mL}$ in the CLED medium were selected for further identification. The colonies found to be lactose and indole positive were considered $E$. coli.

\section{Antibiotic susceptibility testing}

Antibiotic susceptibility tests were performed according to Clinical and Laboratory Standards Institute (CLSI) recommendations [10] at the Enzilab laboratory, using the disk diffusion method on Mueller Hinton agar (Oxoid, Basingstoke, UK) to test the following antibiotics: ampicillin $(10 \mu \mathrm{g})$; different generations of cephalosporin (cephalotin [30 $\mu \mathrm{g}]$, cefoxitin $\left[\begin{array}{ll}30 & \mu \mathrm{g}\end{array}\right]$, ceftriaxone $\left[\begin{array}{ll}30 & \mu \mathrm{g}\end{array}\right]$ ); SMT $(1.25 / 23.75 \mu \mathrm{g}) ;$ the aminoglycosides (gentamicin $[120 \mu \mathrm{g}]$, amikacin [30 $\mu \mathrm{g}]$ ); quinolones (norfloxacin [10 $\mu \mathrm{g}$ ], ciprofloxacin [5 $\mu \mathrm{g}$ ], levofloxacin [5 $\mu \mathrm{g}]$ ); nalidixic acid $(30 \mu \mathrm{g})$; and nitrofurantoin $(300 \mu \mathrm{g})$.

\section{Strain archival}

To perform molecular analysis, E. coli colonies were grown in Mueller Hinton medium tubes containing TSB/glycerol (20\%) medium (Oxoid, Basingstoke, UK) and stored at $-20^{\circ} \mathrm{C}$. Microorganisms were resuscitated from the storage medium in brain-heart infusion (BHI) broth (Oxoid, Basingstoke, UK) for 24 hours at $37^{\circ} \mathrm{C}$ and then streaked on nutrient agar and grown for 24 hours at $37^{\circ} \mathrm{C}$.

\section{Polymerase chain reaction (PCR)}

For molecular analysis, one isolated colony was subcultured in fresh BHI broth and incubated for 24 more hours at $37^{\circ} \mathrm{C}$. E. coli isolates were centrifuged for 2 minutes at $13.000 \mathrm{rpm}$, and the supernatant was discarded. Bacterial pellets were then re-suspended in $100 \mu \mathrm{L}$ of sterile distilled water (MilliQ), boiled for 10 minutes, centrifuged for 2 more minutes at 13.000 $\mathrm{rpm}$, and $100 \mu \mathrm{L}$ of the supernatant was transferred to another tube. Polymerase chain reaction was performed according to Blahna et al. (2006) [9]. For amplification of the sul2 gene, sul2-F primers were used (5'- GCGCTCAAGGCAGATGGCATT - 3') and sul2-B (5'- GCGTTTGATACCGGCACCCGT - 3'). For the amplification of a 16S rRNA gene fragment to act as a positive control, the 16S-F (5'GCGGACGGGTGAGTAATGT-3') and 16S-B (5'TCATCCTCTCAGACCAGCTA 3') primers were used. The reaction volume was $50 \mu \mathrm{L}$ and contained 3 $\mu \mathrm{L}$ of the DNA boiled cell lysate, $0.3 \mu \mathrm{M}$ sul2B and sul2F primers, $0.15 \mu \mathrm{M} 16 \mathrm{SF}$ and $16 \mathrm{SB}, 1 \mathrm{x}$ PCR buffer $(200 \mathrm{mM}$ Tris- $\mathrm{HCl} \mathrm{pH} 8.4,500 \mathrm{mM} \mathrm{kCl}), 3$ $\mathrm{mM} \mathrm{MgCl}_{2}, 0.2 \mu \mathrm{M}$ dNTPs (Invitrogen, Carlsbad, USA), and 1.25 U Platinum Taq DNA polymerase (Invitrogen, Carlsbad, USA). The amplified PCR product was subjected to electrophoresis.

\section{Statistical analysis}

Statistical analysis was performed with the BioStat 4.0 program, using the Chi-square test with a significance level of greater than $95 \%(p<0.05)$.

\section{Results}

The antibiotic susceptibility profiles of 739 urinary isolates of $E$. coli were analyzed. Most isolates $(87.3 \%)$ originated from outpatients. The highest number of isolates were resistant to ampicillin, with $57.4 \%$ of isolates from hospital settings and $38.9 \%$ of isolates from outpatient units $(\mathrm{p}=0.04)$ displaying resistance to this antibiotic. 
The resistance to SMT in hospital settings was $44.7 \%$, and for outpatients, a resistance rate of $33.2 \%$ was observed; this was not a statistically significant difference $(\mathrm{p}=0.14)$. However, a significant difference $(\mathrm{p}<0.0001)$ was detected between the levels of resistance to cephalotin when the hospital isolates $(38.3 \%)$ were compared to isolates obtained from outpatients $(16.3 \%)$.

In addition, there were statistically significant differences in the levels of resistance between isolates from hospital and outpatient settings for nalidixic acid $(\mathrm{p}<0.0001)$, norfloxacin $(\mathrm{p}<0.0001)$, levofloxacin $(\mathrm{p}$ $<0.0001)$, ciprofloxacin $(\mathrm{p}<0.0001)$, gentamicin $(\mathrm{p}<$ $0.0001)$, nitrofurantoin $(\mathrm{p}<0.0001)$, cefoxitin $(\mathrm{p}<$ $0.0001)$, and ceftriaxone $(p<0.0001)$. Among the isolates resistant to amikacin, there was no significant difference between the two settings $(\mathrm{p}=0.20)$.

Figure 1 shows the levels of resistance to the tested antibiotics. Resistance in isolates obtained from hospitalized patients was higher compared to the levels observed for outpatient samples. Nevertheless, for the SMT combination, there was no significant difference between the two settings.

Polymerase chain reaction was performed on 100 isolates that were resistant to trimethoprimsulfamethoxazole, and 21 susceptible isolates were used as the negative controls. The genomic region coding for $16 \mathrm{~S}$ ribosomal RNA was amplified for all isolates, confirming the presence of amplifiable $E$. coli DNA. Among the susceptible isolates, there was no amplification of the sul2 gene. The sul2 gene was detected in $67 \%$ of the $E$. coli isolates characterized as resistant to trimethoprim-sulfamethoxazole.

Of the 100 analyzed samples, 72 were collected from outpatients and 28 were from hospitalized patients. Of the 72 outpatient samples, $48(66.7 \%)$ had the sul 2 gene. Of the 28 hospital samples, $19(67.9 \%)$ had the sul2 gene.

\section{Discussion}

High levels of resistance to antibiotic agents limit the therapeutic options utilizing first-choice antibiotic agents to treat UTIs. To control the expansion of resistant bacteria, data on local, regional and national resistance levels should be used to assist in the development of efficient intervention strategies. The levels of resistance to ampicillin, sulfamethoxazole trimethoprim, cephalotin, nalidixic acid, norfloxacin, and ciprofloxacin are a warning sign, and, thus, precautions should be taken in the empirical use of these antibiotics.
For the antibiotic ampicillin, the resistance level of $38.9 \%$ observed in our study in the outpatient isolates diverges from previously published studies, namely a study involving different countries in Latin America (Argentina, Chile, Brazil, Venezuela, and Mexico) (53.6\% resistance) [11]. Another study conducted in the State of Paraná in Brazil observed a $62.1 \%$ resistance [12], and in Mexico, a 74\% resistance to ampicillin was detected [13]. These studies demonstrated very high levels of resistance to ampicillin with regional variation. These differences were detected because the use of ampicillin might have been more prevalent in regions with higher levels of resistance [14]. The level of resistance we observed in hospital settings for the antibiotic ampicillin $(57.4 \%)$ was high and similar to those described in studies conducted by Bean et al. (2008) in the city of London (65\% resistance) [15], in Leon, Nicaragua $(61.4 \%)$ [16], and in the state of Santa Catarina, Brazil (60.4\% resistance) [17].

In the present study, the resistance level to the antibiotic cephalotin (16.3\%) in the outpatient setting was different from that found by Dias Neto et al. (2003) (42\% resistance) [18] and in Paraná State, Brazil (22.8\% resistance) [12]. The present study was conducted in a smaller town than the other two studies, leading to a lower chance of movement of resistant strains compared to larger centers. In our study, the resistance level observed for nalidixic acid was $14.1 \%$ for outpatient samples and $35.1 \%$ for inpatient samples, which was lesser than reported by Andrade et al. (2006) [11] who observed, in outpatients from

Figure 1: Resistance of isolates of $E$. coli to antibiotics. AMP: ampicillin; SXT: trimethoprim-sulfamethoxazole; CEF: cephalotin; NAL: nalidixic acid; NOR: norfloxacin; CIP: ciprofloxacin; LVX: levofloxacin; NIT: nitrofurantoin; GEN: gentamicin; FOX: cefoxitin; AMK: amikacin; CRO: ceftriaxone

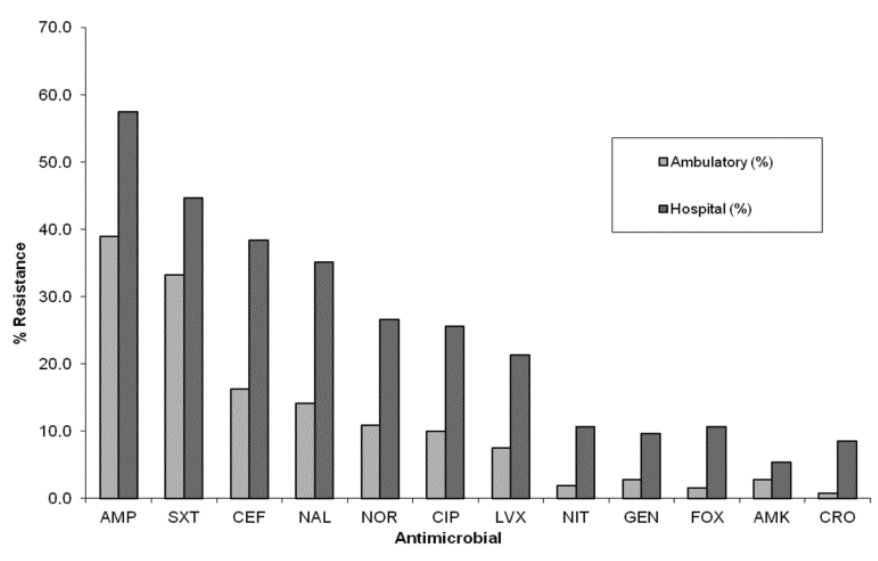


different countries of Latin America, a 29.3\% resistance to this antibiotic.

The level of resistance to cephalosporin in the hospital setting was many times higher compared to the level in the community. The selective pressure exerted by a continuous use of antibiotics in hospital environments favors the selection and circulation of resistant strains [19]. We also observed in our study that cephalotin, a first generation of cephalosporin, presented higher levels than the other tested generations, similar to a previous study [18].

The level of resistance found for SMT (33.2\%) in outpatient settings in the present study was lesser than the level reported by Andrade et al. in 2006 (40.4\%) in different Latin American countries [11]. Regarding the levels of resistance to this antibiotic in the hospital setting, the rates observed in the present study (44.7\%) are higher than rates reported by Bours et al. in 2010 $(38.6 \%)$ [16]. Such discrepancies demonstrate that resistance to this antibiotic varies in different locations, likely because it is widely prescribed, and misuse includes its use in self-medication.

Resistance to SMT has been correlated with the presence of the sul2 gene in a number of different studies. In the present study, the sul2 gene was detected in $66.7 \%$ of outpatient samples. This rate is somewhat lower than that reported by Blahna et al. (2006) [9] in Europe and Canada, who confirmed presence of the gene in $77.9 \%$ of the isolates assessed. The remaining isolates studied (33.3\%) that did not possess the sul2 gene can be assumed to have other mechanisms of resistance, such as the sull and sul3 genes, which were not evaluated in this study [9].

Of the isolates obtained from hospital settings, the sul2 gene was found in $67.9 \%$ of them, which differs from the findings of Bean et al. (2005) [15] in the city of London. This author also noticed an increase in the presence of this gene over time. In 1991, the gene was observed in $67 \%$ of the isolates; in $1999,79 \%$ of the isolates contained the gene, and in $2004,81 \%$ of the isolates had the gene, indicating an increase in acquisition of the gene over time.

Frank et al. (2007) [20] conducted a study in Central Africa that assessed 78 clinical Enterobacteriaceae and described the presence of the sul2 gene in $86 \%$ of the inpatient and outpatient isolates studied. In the present study, the sul2 gene was detected in a lower number of SMT-resistant isolates than in other studies carried out in different countries and different continents. This can be explained by regional variations and by the acquisition of genes involved in resistance to sulfametoxazole.
Additionally, because the susceptibility test is performed with trimethoprim, resistance could be solely to trimethoprim and not to sulfamethoxazole.

The high prevalence of the sul2 gene demonstrated in this study is of concern because when there is resistance associated with the presence of movable DNA elements, such as plasmids, it may be difficult to eliminate resistance, which tends to increase over time.

\section{Acknowledgements}

We thank the University of Santa Cruz do Sul for financial support and for the availability of a scientific initiation grant.

\section{References}

1. Wilson ML, Gaido L (2004) Laboratory diagnosis of urinary tract infections in adult patients. Clin Infect Dis 388: 11501158.

2. Kariuki S, Revathi G, Corkill J, Kiiru J, Mwituria J, Mirza N, Hart CA (2007) Escherichia coli from community-acquired urinary tract infections resistant to fluoroquinolones and extended-spectrum beta-lactams. J Infect Dev Ctries 1: 257262.

3. Ronald A (2002) The etiology of urinary tract infection: traditional and emerging pathogens. Am J Med 1: 14S-19S.

4. Stamm WE (1991) Catheter-associated urinary tract infections: epidemiology, pathogenesis, and prevention. Am J Med 91: 65S-71S.

5. Watts RE, Hancock V, Ong CL, Vejborg RM, Mabbett AN, Totsika M, Looke D F, Nimmo GR, Klemm P, Schembri MA (2010) Escherichia coli isolates causing asymptomatic bacteriuria in catheterized and noncatheterized individuals possess similar virulence properties. J Clin Microbiol 48: 2449-2458.

6. Karlowsky JA, Kelly LJ, Thornsberry C, Jones ME, Sahm DF (2002) Trends in antimicrobial resistance among urinary tract infection isolates of Escherichia coli from female outpatients in the United States. Antimicrob Agents Chemother. 46: 2540-2545.

7. Aypak C, Altunsoy A, Düzgün N (2009) Empiric antibiotic therapy in acute uncomplicated urinary tract infections and fluoroquinolone resistance: a prospective observational study. Ann Clin Microbiol Antimicrob 8: 27.

8. Sköld O (2001) Resistance to trimethoprim and sulfonamides. Vet Res 32: 261-273.

9. Blahna MT, Zalewski CA, Reuer J, Kahlmeter G, Foxman B, Marrs CF (2006) The role of horizontal gene transfer in the spread of trimethoprim-sulfamethoxazole resistance among uropathogenic Escherichia coli in Europe and Canada. J Antimicrob Chemother 574: 666-672.

10. National Committee e for Clinical Laboratory Standards. Performance standards for antimicrobial susceptibility testing; Twenty-first informational supplement. (2011); 31(1) M100S21. 
11. Andrade SS, Sader HS, Jones RN, Pereira AS, Pignatari AC, Gales AC (2006) Increased resistance to first-line agents among bacterial pathogens isolated from urinary tract infections in Latin America: time for local guidelines? Mem Inst Oswaldo Cruz 101: 741-748.

12. Esmerino LA, Gonçalves LG, Schelesky ME (2003) Perfil de sensibilidade antimicrobiana de cepas de Escherichia coli isoladas de infecções urinárias comunitárias. UPEG Ciências, Biologia e Saúde 9: 31-39.

13. Arredondo-García JL, Amábile-Cuevas CF (2008) High resistance prevalence towards ampicillin, co-trimoxazole and ciprofloxacin, among uropathogenic Escherichia coli isolates in Mexico City. J Infect Dev Ctries 2: 350-353.

14. Wirtz VJ, Dreser A, Gonzales R (2010) Trends in antibiotic utilization in eight Latin American countries, 1997-2007. Rev Panam Salud Publica. 27: 219-225.

15. Bean DC, Krahe D, Wareham DW (2008) Antimicrobial resistance in community and nosocomial Escherichia coli urinary tract isolates, London 2005-2006. Ann Clin Microbiol Antimicrob 7: 13.

16. Bours PH, Polak R, Hoepelman AI, Delgado E, Jarquin A, Matute AJ (2010) Increasing resistance in communityacquired urinary tract infections in Latin America, five years after the implementation of national therapeutic guidelines. Int J Infect Dis 14: 770-774.
17. Blatt JM, Miranda MC (2005) Perfil dos microrganismos causadores de infecções do trato urinário em pacientes internados. Revista Panam Infectol 7: 10-14.

18. Dias Neto JA, Silva LDM, Martins ACP, Tiraboschi RB, Domingos ALA, Suaid HJ, Tucci SJ, Cologna AJ (2003) Prevalence and bacterial susceptibility of hospital acquired urinary tract infection. Acta Cir Bras 18: 36-38.

19. Kolar M, Urbanek K, Latal T (2001) Antibiotic selective pressure and development of bacterial resistance. International Journal of Antimicrobial Agents 17: 357-363.

20. Frank T, Gautier V, Talarmin A, Bercion R, Arlet G (2007) Characterization of sulphonamide resistance genes and class 1 integron gene cassettes in Enterobacteriaceae, Central African Republic (CAR). J Antimicrob Chemother 59: 742-745.

\section{Corresponding author}

Andréia Rosane de Moura Valim

Rua Gaspar Silveira Martins 888/05 - Bairro Santo Inácio

Santa Cruz do Sul - RS - Brazil, Cep- 96820-002

Phone: $55513717-7341$ or 5551 9335-7393

Email: avalim@unisc.br

Conflict of interests: No conflict of interests is declared. 